\author{
RESEARCH ARTICLE \\ 10.1029/2018JB017236 \\ Key Points: \\ - A lognormal probability distribution \\ consistently models offshore \\ landslide size distributions of \\ siliciclastic margins \\ - Comparison of 10 margins around \\ the world indicates significant \\ differences in mean sizes but similar \\ lognormal shape parameters \\ - A procedure is developed to \\ determine offshore landslide hazard \\ curves from size distributions if \\ duration of landslide activity is \\ known
}

Correspondence to:

E. L. Geist,

egeist@usgs.gov

Citation:

Geist, E. L., \& ten Brink, U. S. (2019). Offshore landslide hazard curves from mapped landslide size distributions.

Journal of Geophysical Research: Solid

Earth, 124, 3320-3334. https://doi.org/

10.1029/2018JB017236

Received 21 DEC 2018

Accepted 28 MAR 2019

Accepted article online 1 APR 2019

Published online 17 APR 2019
Published 2019. This article is a U.S. Government work and is in the public domain in the USA.

\section{Offshore Landslide Hazard Curves From Mapped Landslide Size Distributions}

\author{
Eric L. Geist ${ }^{1}$ (D) and Uri S. ten Brink ${ }^{2}$ (iD) \\ ${ }^{1}$ U.S. Geological Survey, Menlo Park, CA, USA, ${ }^{2}$ U.S. Geological Survey, Woods Hole, MA, USA
}

\begin{abstract}
We present a method to calculate landslide hazard curves along offshore margins based on size distributions of submarine landslides. The method utilizes 10 different continental margins that were mapped by high-resolution multibeam sonar with landslide scar areas measured by a consistent Geographic Information System procedure. Statistical tests of several different probability distribution models indicate that the lognormal model is most appropriate for these siliciclastic environments, consistent with an earlier study of the U.S. Atlantic margin (Chaytor et al., 2009, https://doi.org/10.1016/j.margeo.2008.08.007).

Parameter estimation is performed using the maximum likelihood technique, and confidence intervals are determined using likelihood profiles. Pairwise comparison of size distributions for the 10 margins indicates that the U.S. Atlantic and Queen Charlotte margins are different than most other margins. These margins represent end-members, with the U.S. Atlantic margin having the highest mean scar area and the Queen Charlotte margin the lowest. We demonstrate that empirical, offshore landslide hazard curves can be developed from the landslide size distributions, if the duration of mapped landslide activity is known. This study indicates that the shape parameter of the size distribution is similar among all 10 margins, and thus, the shape of the hazard curves is also similar. Significant differences in hazard curves among the margins are therefore related to differences in mean sizes and, potentially, differences in the duration of landslide activity.
\end{abstract}

\section{Introduction}

Offshore landslides present direct hazards to wind farms, oil and gas platforms, pipelines, communication cables, and other infrastructure. Landslides also present an indirect hazard by way of the tsunamis they generate. One way landslide hazards can be quantified is by what we term the offshore landslide hazard curve. Hazard curves plot probability of exceedance as a function of a hazard metric, such as peak ground acceleration for earthquakes and peak amplitude for tsunamis. For offshore landslides, the hazard metric is landslide size, represented in this study by the scar area. Scar area is chosen because scar areas and scar volumes in siliciclastic offshore margins were shown to be almost linearly correlated (Chaytor et al., 2009; ten Brink et al., 2014). Onshore, landslide hazard curves can be developed from a geotechnical approach where there is detailed information on the site response to seismic ground shaking, the topographic slope, and subsurface physical properties. For offshore landslides, however, information on site response and subsurface physical properties offshore is rarely available and topographic slope is poorly correlated with the extent of slope failure (ten Brink et al., 2016). Our approach is therefore to empirically develop landslide hazard curves, using the statistics of past offshore landslide sizes and occurrence. Observations of landslide size distribution are easily obtainable using seafloor mapping tools and are a key ingredient in developing the empirical landslide hazard curve. The size distribution is also important for aggregating landslide sources in the development of tsunami hazard curves (Geist et al., 2009; Geist \& Lynett, 2014; Grezio et al., 2017; Lane et al., 2016).

It has previously been noted that there is a distinct difference in the sizes of offshore landslides along seismically active margins compared to rarely active (commonly known as "passive") margins (McAdoo et al., 2000; Urgeles \& Camerlenghi, 2013). The paradox is that the largest landslides commonly occur along rarely active margins, where the frequency and severity of ground shaking from earthquakes is lower than in active margins. Recently, ten Brink et al. (2016) correlated the fraction of each margin covered by observed landslide scars with a combined factor that includes sedimentation rate and earthquake recurrence, both taken from the published literature. Landslide scars along the margin increase exponentially with the average sediment thickness that accumulates during a mean interseismic interval. In addition, their analysis shows that sedimentation rate and earthquake recurrence are independent variables and that the slope angle does not affect landslide distribution. Their interpretation of the empirical 
correlation is that cyclic loading by seismic shaking increases the sediment strength for future shaking, by rearranging the grains and decreasing the pore pressure (Lee et al., 2004; Strozyk et al., 2010). As explained by ten Brink et al. (2016), some deviations in the correlation may be caused by rapid oversteepening of the slope in tectonically active regions.

The primary objective of this study is to quantitatively estimate the probability distribution of landslide sizes along the margins examined by ten Brink et al. (2016), both rarely active and active. Chaytor et al. (2009) and ten Brink et al. (2009) noted that the composition of landslide material has an effect on the distribution that best fits the data. Whereas failure of carbonate platforms tend to be distributed according to a power law (ten Brink et al., 2006), failures of siliciclastic material follow a lognormal distribution, although Urgeles and Camerlenghi (2013) suggest that landslides in the Mediterranean Sea also follow a power law. In this study, because all of the margins are dominated by siliciclastic material, we will focus on the lognormal model. To verify that the lognormal model is the distribution that best fits these margins, in section 3 we statistically evaluate the lognormal model relative to other possible relevant models including the power law. In section 4, we propose a procedure to develop the offshore landslide hazard curve, which involves estimating the duration of landslide activity in addition to the size distribution. A previous study examined the details of the temporal distribution of failures at an Integrated Ocean Drilling Program site containing repeated mass transport deposits (Geist et al., 2013) that complements the results of this study.

\section{Data}

Multibeam bathymetric surveys used to establish landslide size distributions for 10 different margins (Figure 1) have been compiled by ten Brink et al. (2016). These margins span a range of sedimentation rates and mean earthquake recurrence rates. The multibeam data have different spatial resolutions, depending on the survey, but identical Geographic Information System-based analysis methods were used to estimate individual scar areas for each margin (Chaytor et al., 2009; ten Brink et al., 2006). The scar areas are defined by an excavation region partly surrounded by scarps that break the local slope. All the scar areas were identified on 1;100,000 scale maps regardless of grid resolution. Scars along submarine canyons were ignored because they probably formed by collapses into deepening channels, and not by ground shaking. In addition, only the continental slope is examined along the margins, ignoring landslides that, for example, occur on the continental rise of the U.S. Atlantic (Chaytor et al., 2009).

The 10 margins shown in Figure 1 include Washington and northern Oregon (north of $45.1^{\circ}$, termed Cascadia North), S. Oregon (termed Cascadia South), El-Salvador-Guatemala, Nicaragua-northern Costa Rica, Makran, and northern Sumatra, where plate subduction is taking place, the convergent margin of Muertos (northern Caribbean), the transpressive margin of Queen Charlotte Fault at Haida Gwaii, Canada, and the rarely active margins of southern New England (U.S. Atlantic margin) and Israel. These margins are associated with a range of earthquake frequencies, sedimentation rates, slope gradients, and morphological profiles. These margins were selected because high-resolution multibeam bathymetry was available over large contiguous areas of the continental slope with along-strike length $>100 \mathrm{~km}$. Additional description of the mapping methods, polygon data, and data sources is given in ten Brink et al. (2016).

\section{Estimation of Landslide Size Distributions}

Based on previous studies (Chaytor et al., 2009; ten Brink, Barkan, et al., 2009), the lognormal distribution appears to be an appropriate initial probability model for landslides involving siliclastic sediment. We first estimate the parameters for the lognormal model specific to each of the regions and then evaluate the model in comparison to other probability distributions below. The probability density function (pdf) for the lognormal distribution of landslide scar areas $f(a)$ is given by

$$
f(a)=\frac{1}{\sqrt{2 \pi} \sigma a} e^{-\frac{[\ln (a)-\mu]^{2}}{2 \sigma^{2}}},
$$

where $\mu$ is a location parameter and $\sigma$ is a shape parameter. The expected value (i.e., mean) for the lognormal distribution is given by $\exp \left(\mu+\sigma^{2} / 2\right)$, the variance by $\left[\exp \left(\sigma^{2}\right)-1\right] \exp \left(2 \mu+\sigma^{2}\right)$, and median by $\exp (\mu)$. Size distributions are often displayed as the complement to the cumulative distribution function, also known as 

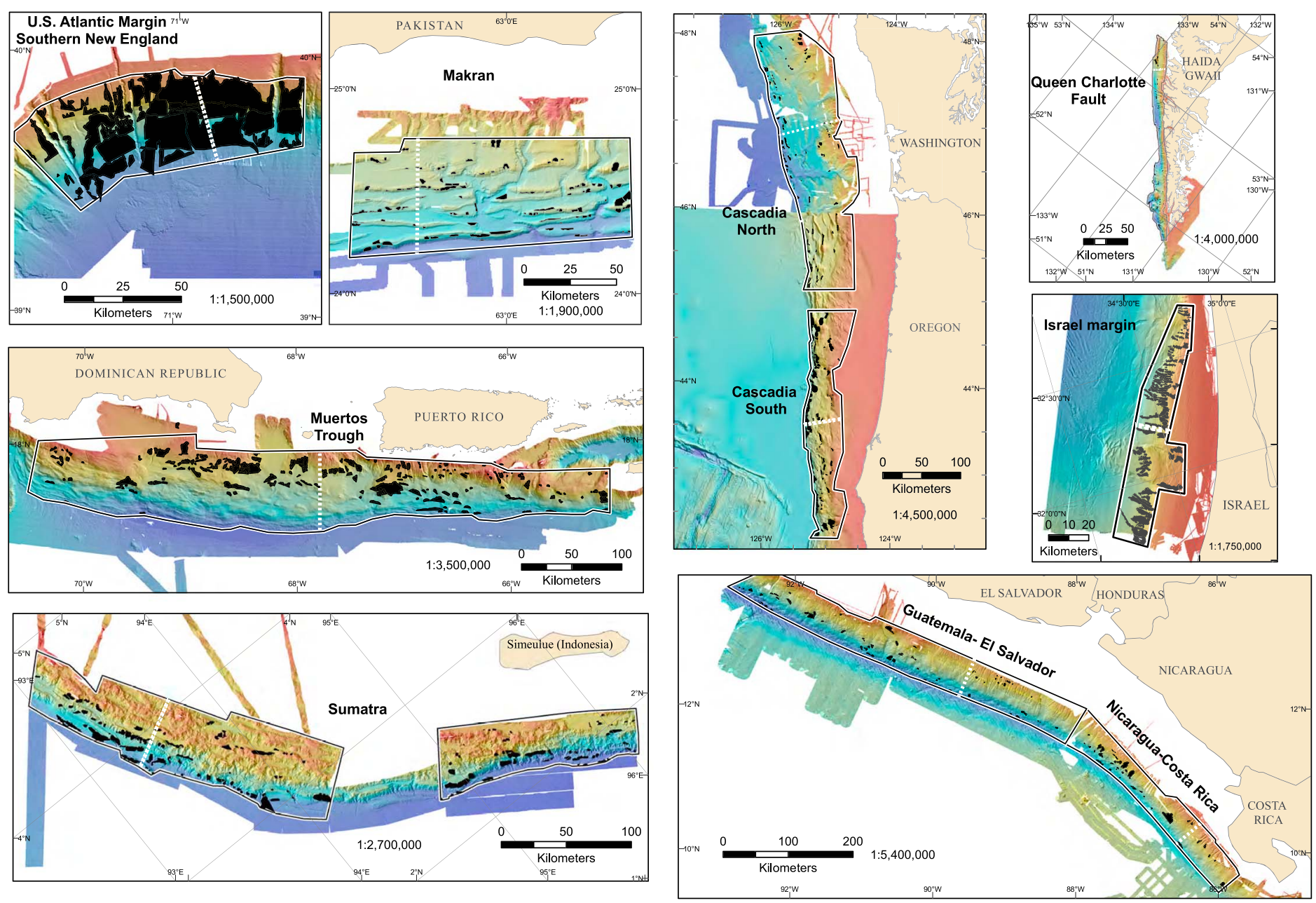

Figure 1. Location maps and scar areas (black) of 10 margins analyzed in this study. From ten Brink et al. (2016).

the survival function. The survival function yields the probability that a landslide greater than a particular size will occur, which is important for hazard calculations. For the lognormal distribution, the survival function is given by

$$
1-F(a)=\frac{1}{2}-\frac{1}{2} \operatorname{erf}\left(\frac{\ln a-\mu}{\sqrt{2} \sigma}\right)
$$

where erf is the error function.

\subsection{Method}

We use the maximum likelihood method to estimate the parameters of the lognormal distribution. For a given probability distribution, the likelihood function represents how likely a set of data points would be observed for a specific set of distribution parameters (Aitkin, 2010). The log-likelihood function $(\ell)$ associated with the lognormal distribution is given by

$$
\begin{gathered}
l\left(\mu, \sigma \mid a_{1}, a_{2}, \ldots a_{n}\right) \\
=-\frac{n}{2} \ln \left(2 \pi \sigma^{2}\right)-\sum_{i=1}^{n} \ln \left(a_{i}\right)-\frac{\sum_{i=1}^{n}\left[\ln \left(a_{i}\right)-\mu\right]^{2}}{2 \sigma^{2}}
\end{gathered}
$$

The optimal parameters are those that represent the maximum in the log-likelihood function, termed the maximum likelihood estimate (MLE). Equations for the MLE of the lognormal parameters are given below: 


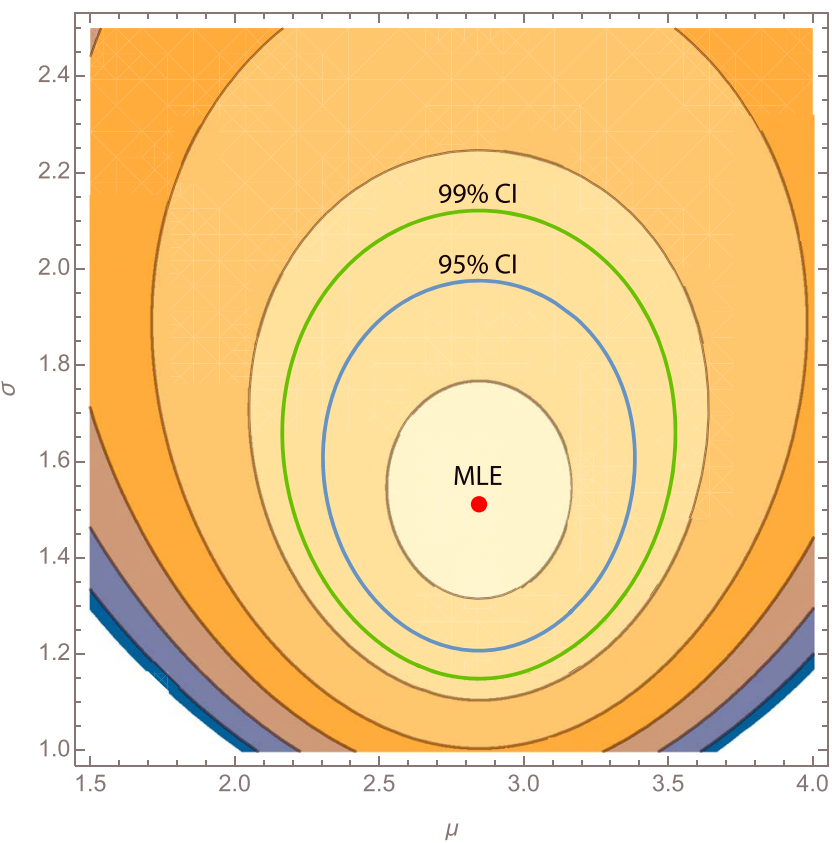

Figure 2. Likelihood contour map for two parameters of lognormal distribution $(\mu, \sigma)$ using the U.S. Atlantic data set. Maximum likelihood estimate (MLE) shown by a red dot. The $95 \%$ and $99 \%$ confidence intervals (CI) are shown by blue and green contours, respectively.

$$
\widehat{\mu}=\frac{\sum_{i=1}^{n} \ln \left(a_{i}\right)}{n} \text { and } \widehat{\sigma}^{2}=\frac{\sum_{i=1}^{n}\left(\ln \left(a_{i}\right)-\frac{\sum_{i=1}^{n} \ln \left(a_{i}\right)}{n}\right)^{2}}{n}
$$

Shown in Figure 2 is a contour plot of the log-likelihood function for landslides along the U.S. Atlantic margin, along with the MLE of the optimal parameters shown by the red dot. The major and minor axes of the contour region are approximately parallel to the $\mu$ and $\sigma$ axes, indicating that the two parameter estimates are not correlated.

Confidence intervals for each parameter are established using likelihood profiles. A likelihood profile is determined by fixing one of the parameters at its MLE and calculating the likelihood as a function of the other free parameter (Aitkin, 2010; Pawitan, 2001). The likelihood profile is defined as

$$
\left[\widehat{\theta}_{L}, \widehat{\theta}_{U}\right]=\left\{\theta ; 2[\ell(\widehat{\theta})-\ell(\theta)]<\chi_{95 \%}^{2}[1]\right\}
$$

where $\widehat{\theta}_{L}, \widehat{\theta}_{U}$ are the lower and upper bounds, respectively, of each of the distribution parameters and $\chi_{95 \%}^{2}[1]$ chi-square distribution with 1 degree of freedom.

To determine whether the lognormal distribution with the estimated parameters is an appropriate model for each margin, we apply a goodness-of-fit hypothesis test. The most common test is the one-sample Kolmogorov-Smirnov (K-S) test. However, we examine the statistical power of the K-S test along with a number of other tests and determine that the Cramér von Mises (CvM) test (Conover, 1971) performs better for these data than the one-sample $\mathrm{K}-\mathrm{S}$ test. We report $p$ values that indicate the probability of obtaining a result equal to or more extreme than what was observed, given the null hypothesis that the data follow a lognormal distribution. In this study, we reject the null hypothesis (i.e., the lognormal distribution models the data) for $p$ values less than 0.05 .

\subsection{Results}

Estimates of lognormal distribution parameters for scar areas along the 10 margins are listed in Table 1. Also shown are the $95 \%$ confidence intervals for each parameter and the $p$ value from the CvM test. The lognormal model cannot be rejected for any of the margins according to the CvM test. The corrected Akaike information criterion value (AICc) is also listed in Table 1 and is used for comparison with other probability models (not among margins) and is described in section 3.3. Overall, the parameter $\mu$ varies significantly among the 10 margins, with the U.S. Atlantic and Queen Charlotte margins being the high and low end-

Table 1

\begin{tabular}{|c|c|c|c|c|c|c|c|c|}
\hline \multirow[b]{2}{*}{ Region name } & \multirow[b]{2}{*}{ Resolution (m) } & \multirow[b]{2}{*}{$n$} & \multicolumn{2}{|c|}{ MLE } & \multicolumn{2}{|c|}{$95 \%$ confidence } & \multirow[b]{2}{*}{ CvM $p$ value } & \multirow[b]{2}{*}{$\mathrm{AICc}$} \\
\hline & & & $\mu$ & $\sigma$ & $\mu$ & $\sigma$ & & \\
\hline Atlantic (U.S.) & 50 & 50 & 2.84 & 1.51 & $2.32-3.37$ & $1.21-1.98$ & 0.88 & 468.1 \\
\hline Cascadia N. & 100 & 79 & 1.43 & 0.97 & $1.16-1.70$ & $0.81-1.20$ & 0.67 & 446.4 \\
\hline Cascadia S. & 100 & 98 & 2.00 & 1.34 & $1.67-2.33$ & $1.13-1.61$ & 0.67 & 726.3 \\
\hline El Salvador-Guatemala & 100 & 90 & 1.08 & 1.27 & $0.76-1.41$ & $1.07-1.54$ & 0.90 & 493.5 \\
\hline Israel & 50 & 106 & 1.30 & 1.08 & $1.05-1.56$ & $0.92-1.29$ & 0.43 & 594.7 \\
\hline Makran & 100 & 106 & 1.01 & 0.87 & $0.81-1.22$ & $0.74-1.04$ & 0.99 & 486.2 \\
\hline Muertos Trough & 50 & 242 & 1.39 & 1.24 & $1.20-1.59$ & $1.11-1.38$ & 0.84 & 1,463 . \\
\hline Nicaragua & 100 & 55 & 1.23 & 1.33 & $0.79-1.67$ & $1.07-1.71$ & 0.46 & 322.8 \\
\hline Queen Charlotte & 10 & 64 & -2.00 & 1.22 & -2.37 to -1.62 & $0.99-1.54$ & 0.50 & -48.7 \\
\hline Sumatra & 50 & 198 & 1.17 & 1.06 & $0.98-1.35$ & $0.94-1.20$ & 0.84 & 1,047 . \\
\hline
\end{tabular}

Estimated Lognormal Distribution Parameters (From Scar Area Data in Square Kilometers), 95\% Confidence Range, CvM p Values, and AICc

Note. $\mathrm{CvM}=$ Cramér von Mises; $\mathrm{AICc}=$ corrected Akaike information criterion; $\mathrm{MLE}=$ maximum likelihood estimate. 


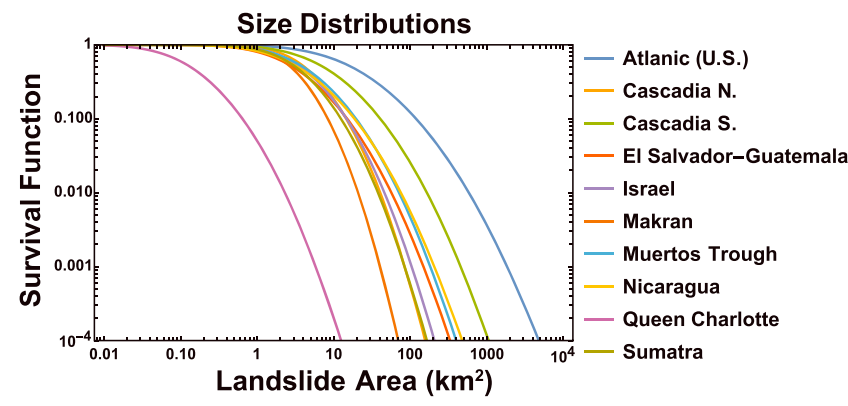

Figure 3. Survival functions (complement of cumulative distribution) of landslide scar areas using the maximum likelihood estimate of lognormal distribution parameters (Table 1).

members, respectively. In contrast, there is much less variation in the $\sigma$ parameter among each of the margins. This is evident in Figure 3, where the survival functions have similar shape in log space, with shifts parallel to the landslide area axis relating to differences in $\mu$.

Data resolution has a slight effect on parameter estimation results, depending on the relation between the minimum scar area and the detection threshold $\left(a_{t}\right)$. The threshold for detection is fixed at a $3 \times 3$ grid cell area, with the resolution for each survey given in Table 1 . The detection threshold for the 50-m-resolution data sets is $a_{t}=0.0225 \mathrm{~km}^{2}$, the $100-\mathrm{m}$ data sets is $a_{t}=0.09 \mathrm{~km}^{2}$, and $10-\mathrm{m}$ data set (Queen Charlotte) is $a_{t}=0.0009 \mathrm{~km}^{2}$. We demonstrate the largest potential effect of data resolution on parameter estimation by examining the end-member case of the Queen Charlotte data set, which has the lowest mean scar area and finest resolution. If we left censor the data set at $a_{t}=0.0225 \mathrm{~km}^{2}$ (i.e., corresponding to 50-m resolution), only one data point is removed and the MLE is only slightly changed $(\widehat{\mu}=-1.96, \widehat{\sigma}=1.20)$. If, however, we left censor the data set at $a_{t}=0.09 \mathrm{~km}^{2}$ (i.e., corresponding to $100-\mathrm{m}$ resolution), more of the data are removed and there is a more significant change in the $\operatorname{MLE}(\widehat{\mu}=-1.28, \widehat{\sigma}=1.00)$. For the other data sets, the bulk of the distribution is greater than the detection threshold and there is little to no effect. Data resolution, however, is an important factor to consider when designing bathymetric surveys of landslide activity.

\subsection{Comparison to Other Model Distributions}

Although the lognormal distribution model has been selected in previous studies (Chaytor et al., 2009) and is a natural distribution to model positive and skewed sizes, it is worthwhile to compare the fit to this model with other possible distributions. We examine two other distributions: the Weibull distribution and the tapered Pareto distribution as described below.

To compare the three distribution models with the landslide data, we use the Akaike information criterion (AIC) based on the log-likelihood function for each distribution. The AIC is evaluated at the maximum value of the likelihood function (Burnham \& Anderson, 2010):

$$
A I C=2 K-2 \max [\ell(\mu, \sigma) \mid a],
$$

where $K$ is the number of distribution parameters. For small samples, there is a correction factor applied to the AIC given by (Burnham \& Anderson, 2010; Hurvich \& Tsai, 1989)

$$
A I C c=A I C+\frac{2 K(K+1)}{n-K-1} .
$$

Table 2

Estimated Weibull Distribution Parameters (From Scar Area Data in Square Kilometers), CvM p Values (Bold: Fails Test), and AICc

\begin{tabular}{lcccc}
\hline \multicolumn{4}{c}{ MLE } & \\
Region name & $\alpha$ & $\beta\left(\mathrm{km}^{2}\right)$ & CvM $p$ value & AICc \\
\hline Atlantic (U.S.) & 0.70 & 36.6 & 0.49 & 473.4 \\
Cascadia N. & 1.22 & 6.64 & 0.70 & 442.3 \\
Cascadia S. & 0.79 & 14.4 & 0.27 & 737.4 \\
El Salvador-Guatemala & 0.83 & 5.54 & 0.49 & 502.7 \\
Israel & 1.00 & 6.31 & 0.54 & 602.1 \\
Makran & 1.18 & 4.27 & 0.31 & 500.9 \\
Muertos Trough & 0.82 & 7.49 & 0.07 & 1501. \\
Nicaragua & 0.68 & 6.89 & $0.07^{\mathrm{a}}$ & 340.5 \\
Queen Charlotte & 0.68 & 0.26 & 0.06 & -21.8 \\
Sumatra & 0.92 & 5.50 & $\mathbf{0 . 0 3}$ & 1087. \\
\hline
\end{tabular}

Note. $\mathrm{CvM}=$ Cramér von Mises; $\mathrm{AICc}=$ corrected Akaike information criterion; MLE = maximum likelihood estimate.

${ }^{\mathrm{a}}$ Fails Kolmogorov-Smirnov test.
The AIC balances the goodness of fit for each distribution with the number of probability parameters $(K)$, although in this study, all three distribution models have two parameters. An alternative method to compare distribution models is use of an $L$-moment diagram (Hosking, 1990) that is based on a weighted combination of the first four statistical moments. Kim et al. (2014) have applied this method to evaluate different distribution models for the spatial variability of tsunami wave heights.

The Weibull distribution is another skewed distribution for nonnegative random variables that is often compared with the lognormal distribution (e.g., Geist et al., 2013). The pdf of the distribution is given by

$$
f(a)=\frac{\alpha}{\beta}\left(\frac{a}{\beta}\right)^{\alpha-1} e^{-\left(\frac{a}{\beta}\right)^{\alpha}},
$$

where $\beta$ is a scale parameter and $\alpha$ is a shape parameter. The mean for this distribution is given by $\beta \Gamma(1+1 / \alpha)$, where $\Gamma$ is the gamma function.

Parameter estimation results for the Weibull distribution using the maximum likelihood technique are given in Table 2. For each margin except 
Table 3

Estimated Tapered Pareto Distribution Parameters (From Scar Area Data in Square Kilometers), CvM p Values (Bold: Fails Test), and AICc

\begin{tabular}{lcccc}
\hline & \multicolumn{2}{c}{ MLE } & & \\
Region name & $\beta$ & $a_{c}\left(\mathrm{~km}^{2}\right)$ & CvM $p$ value & AICc \\
\hline Atlantic (U.S.) & 0.0094 & 51.3 & $\mathbf{0 . 0 1 4}^{\mathrm{a}}$ & 487.0 \\
Cascadia N. & $0.00^{\mathrm{b}}$ & 6.19 & 0.46 & 446.3 \\
Cascadia S. & 0.016 & 17.8 & $\mathbf{0 . 0 1 6}^{\mathrm{a}}$ & 746.3 \\
El Salvador-Guatemala & 0.022 & 6.73 & 0.11 & 502.2 \\
Israel & $0.00^{\mathrm{b}}$ & 6.27 & 0.56 & 601.4 \\
Makran & $0.00^{\mathrm{b}}$ & 3.91 & 0.27 & 501.2 \\
Muertos Trough & $0.00^{\mathrm{b}}$ & 8.51 & $\mathbf{0 . 0 0}^{\mathrm{a}}$ & 1520. \\
Nicaragua & 0.010 & 15.4 & $\mathbf{0 . 0 1 4}^{\mathrm{a}}$ & 353.0 \\
Queen Charlotte & $0.00^{\mathrm{b}}$ & 0.38 & $\mathbf{0 . 0 0}^{\mathrm{a}}$ & 6.28 \\
Sumatra & $0.00^{\mathrm{b}}$ & 5.75 & $\mathbf{0 . 0 0 8 4}^{\mathrm{b}}$ & 1089. \\
\hline
\end{tabular}

Note. $\mathrm{CvM}=$ Cramér von Mises; $\mathrm{AICc}=$ corrected Akaike information criterion; MLE = maximum likelihood estimate.

${ }^{\mathrm{a}}$ Fails Kolmogorov-Smirnov test. ${ }^{\mathrm{b}}$ Shifted exponential distribution.
Sumatra, the Weibull distribution cannot be rejected using the CvM test. For the Nicaragua data set, the distribution fails the K-S test. For each margin except Cascadia North, the AICc value is greater than the AICc for the lognormal distribution, indicating that the lognormal distribution is a better fit.

The tapered Pareto distribution has been used extensively to model the distribution of earthquake sizes (Kagan, 2002a) and has been extended to other natural hazards (Geist \& Parsons, 2014; Vere-Jones et al., 2001). In addition, a power law distribution with an exponential rollover at small sizes has been used to model subaerial landslides (Malamud et al., 2004). Power law type distributions such as these and the lognormal distribution are often indistinguishable over a large range of sizes (Sornette, 2004). The pdf of the tapered Pareto distribution is given by

$$
f(a)=\left[\frac{\beta}{a}+\frac{1}{a_{c}}\right]\left(\frac{a_{t}}{a}\right)^{\beta} \exp \left(\frac{a_{t}-a}{a_{c}}\right) \text { for } a_{t} \leq a,
$$

where $\beta$ is the shape parameter (power law exponent) and $a_{c}$ is a corner size or turning point. The minimum threshold amplitude $a_{t}$ is usually interpreted as a detection threshold and is not an independently estimated parameter. For the multibeam bathymetric surveys, the detection threshold is fixed at a $3 \times 3$ grid cell area, as described in section 3.2. The likelihood function associated with the tapered Pareto distribution is given by Kagan (2002a), and the numerical method to find the MLE is given in Geist and Parsons (2014).

Parameter estimation results for the tapered Pareto distribution are listed in Table 3. For all margins, the power law exponent is very small or 0 , indicating that the exponential term dominates the distribution (equation (9)). Thus, the distribution is more like a shifted exponential distribution, rather than a power law distribution of sizes (see also ten Brink, Barkan, et al., 2009). The distribution can be rejected for 6 of the 10 margins. In each case, the AICc values are higher than the values associated with the lognormal distribution, indicating again than the lognormal distribution is the preferred model.

Figure 4 below shows a comparison of the best fit distributions for the three models, using the U.S. Atlantic margin data set.

\subsection{Are All Margins Different?}

Given the uncertainty in lognormal parameter estimates (Table 1), it is worthwhile to perform a pairwise test of the margins to determine whether differences in landslide distributions are statistically significant. Because the size distribution forms the basis of all hazard assessments, statistically significant differences in distributions between margins point to differences in the relative hazard. We employ two different tests: (1) the $z$ test modified for the lognormal distribution and (2) the two-sample K-S test.

For the first test, the MLE of the two lognormal parameters are used to calculate a $z$ score as developed by Zhou et al. (1997):

$$
z=\frac{\widehat{\mu}_{2}-\widehat{\mu}_{1}+\frac{1}{2}\left(\widehat{\sigma}_{2}^{2}-\widehat{\sigma}_{1}^{2}\right)}{\sqrt{\frac{\widehat{\sigma}_{1}^{2}}{n_{1}}+\frac{\widehat{\sigma}_{2}^{2}}{n_{2}}+\frac{1}{2}\left(\frac{\widehat{\sigma}_{1}^{4}}{n_{1}-1}+\frac{\widehat{\sigma}_{2}^{4}}{n_{2}-1}\right)}}
$$

Under the null hypothesis that two populations are drawn from the same distribution, $z$ would follow a standard normal distribution. Results from a pairwise comparison using this $z$ test are shown in Figure 5. Of note, we can reject the hypothesis that the landslide distribution along the U.S. Atlantic is the same as most other margins. The U.S. Atlantic has the highest mean sizes. On the other end of the spectrum, the Queen Charlotte margin has the lowest mean sizes and is also unlike most other margins.
Figure 4. Survival functions for three probability models in comparison to the empirical distribution function (EDF) for the U.S. Atlantic data set. 


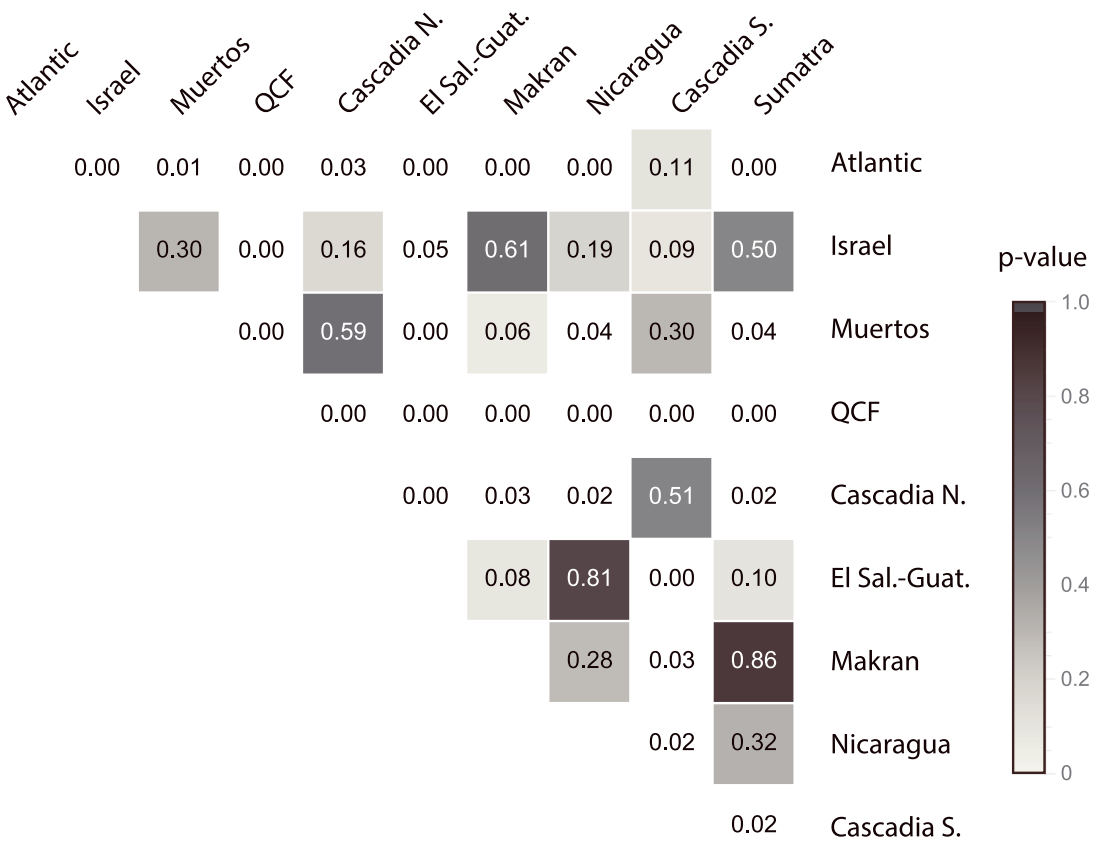

Sumatra

Figure 5. Pairwise comparison of margins using the $z$ test. Color-shaded pairs cannot reject the null hypothesis that the distribution of landslide sizes is the same.

Pairs of margins in geographic proximity to one another appear to have similar landslide distributions, owing possibly to a similar depositional environment and mean recurrence time of triggering earthquakes.

The second test is a nonparametric test, the two-sample K-S test, based on the null hypothesis that the data come from the same distribution (Conover, 1971; Gibbons \& Chakraborti, 2004). Note in this case we care comparing two data sets directly without specifying a particular probability model. Results using the twosample K-S test are shown in Figure 6 indicate that more margin pairs are rejected as having the same size distribution compared to the $z$ test.

\subsection{Relation to Total Scar Area}

The total area of the margin that has failed in landslides, as evidenced by the scars, can be directly related to the estimated probability distributions. The total scar area $(A)$ is given by the expected (mean) value of the distribution and the number of landslides $n$ :

$$
A=n \exp \left(\mu+\frac{\sigma^{2}}{2}\right)
$$

To further evaluate the appropriateness of the lognormal model, we plot the expected mean from the lognormal distribution against the observed sample mean (Figure 7a). We also plot the total of scar areas from mapping and the total scar area estimated from the probability distribution using equation (11) (Figure 7b). In both cases, we see a close correspondence between predicted and observed values.

\subsection{Effect of Finite Sampling on Area Sums}

To determine the effect of finite sampling on the total landslide area and scar fraction for a margin, we create synthetic landslide catalogs using the estimated lognormal distribution. For example, Figure 8 shows 10 synthetic landslide catalogs (thin blue lines) sampled from the parent distribution for the U.S. Atlantic margin, in this case our MLE distribution (heavy red line). The same number of landslides as in the observed catalog ( $n=50)$ was used to create the synthetic catalogs. The heavy blue line shows the observed empirical 


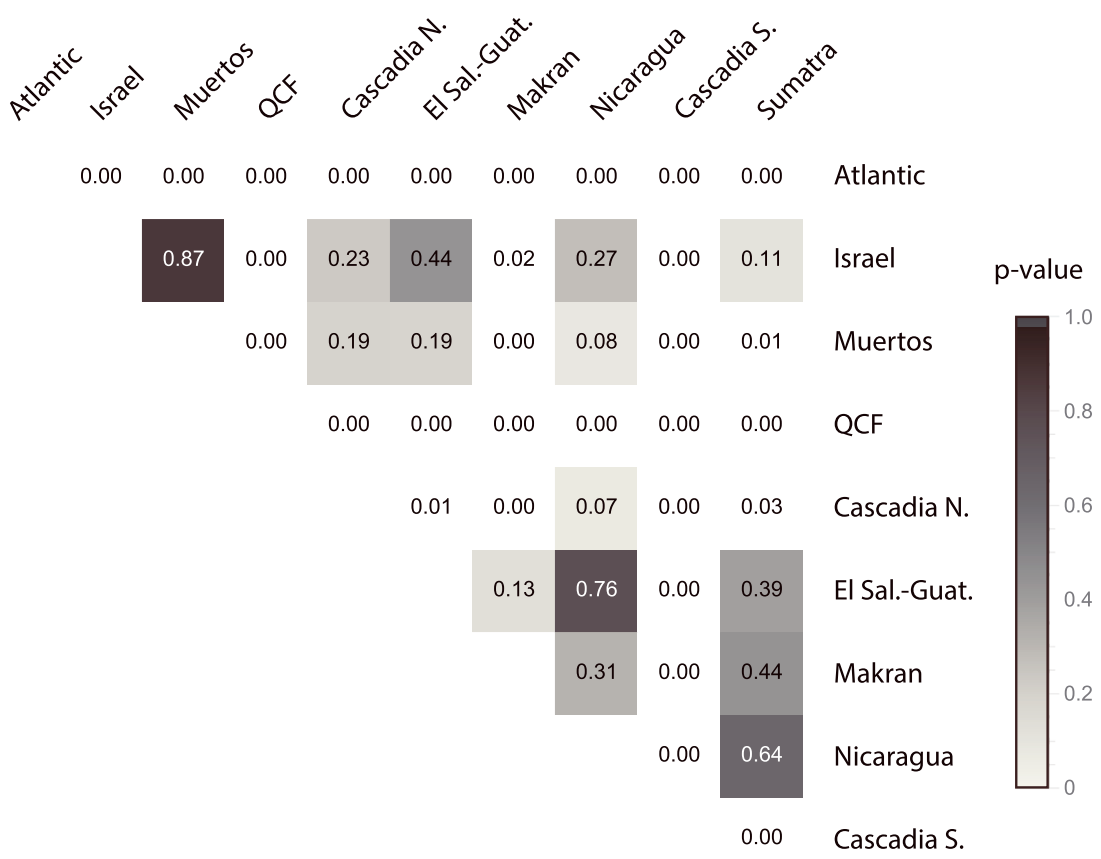

Sumatra

Figure 6. Pairwise comparison of margins using the two-sample Kolmogorov-Smirnov test. Color-shaded pairs cannot reject the null hypothesis that the distribution of landslide sizes is the same.

distribution. The range of total landslide area is $1,933-3,144 \mathrm{~km}^{2}$, which would vary slightly for a different set of 10 synthetic landslide catalogs.

We repeat this procedure for each margin, using 100 synthetic catalogs and the margin-specific MLE distribution. Because each margin has a different catalog length $(n)$ listed in Table 1, the effect of random sampling on total landslide area will vary as shown by the box plots in Figure 9a. Smaller catalog lengths such as for the U.S. Atlantic and Nicaragua result in larger variation in total area. The effect of finite sampling also extends to estimates of the scar fraction as well (Figure 9b). The scar fraction normalizes the data sets according to the area of the margin that is mapped.

The 10 different data sets can be nondimensionalized and aggregated together, as indicated by Choi et al. $(2006,2002)$ who examine the lognormal distribution applied to the spatial variability of tsunami wave heights at the coast. The nondimensional scar area is given by $\zeta=\left(\frac{a}{\bar{a}}\right)^{1 / \sigma}$, where $\bar{a}=e^{\mu}$ is the geometric mean for each data set. Accordingly, the distribution that describes the nondimensional data is a special case of the lognormal distribution where $\mu=0$ and $\sigma=1$, also known as Gibrat's distribution, with survival function

$$
1-F(\zeta)=\frac{1}{2}-\frac{1}{2} \operatorname{erf}\left(\frac{\ln \zeta}{\sqrt{2}}\right)
$$

Shown in Figure 10 is the empirical distribution function for all of the data from the 10 data sets $(n=1,088)$ along with the distribution given by equation (12). A close match is observed.

In terms of determining how large an area needs to be mapped in order to accurately assess landslide statistics, uncertainty in scar fraction depends only on the total number of mapped landslides rather than the mapped area. Regions with low landslide activity will likely need a larger mapped area. A larger mapped area would also be needed to account for any spatial variation in depositional patterns. For the margins analyzed in this study, each of the mapped regions is large enough to encompass a sufficient number of landslides (nominally, $n>30$ ) to estimate the probability distribution. As indicated in section 3.2, it is also important to consider the resolution of the multibeam bathymetry relative to the smallest minimum expected scar areas. 

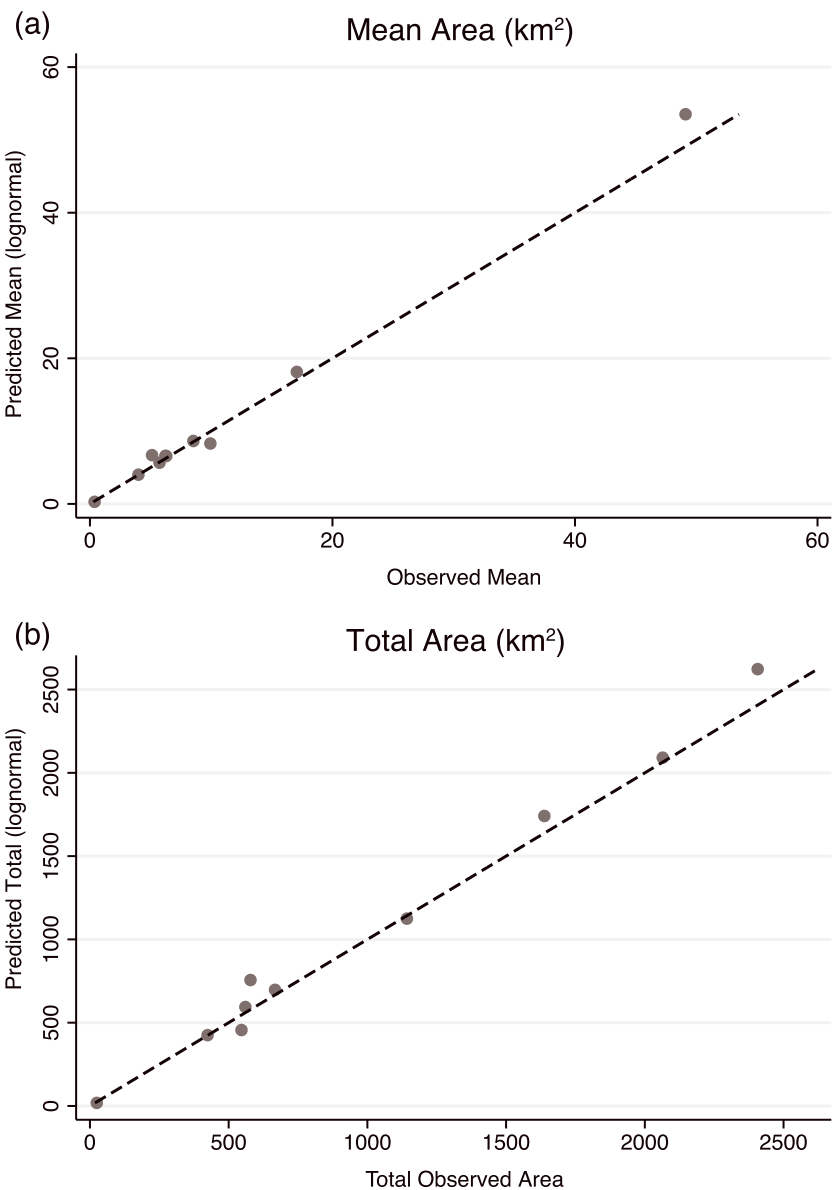

Figure 7. Comparison of observed and predicted scar areas $\left(\mathrm{km}^{2}\right)$ in evaluating the maximum likelihood estimate lognormal model: (a) mean area and (b) total area. Dashed line is 1:1 reference.

\section{Development of Offshore Landslide Hazard Curves}

An offshore landslide hazard curve plots exceedance probability or rate as a function of a hazard metric: in this case, scar area. The hazard curve can be determined from the landslide size distribution derived in section 3 if the duration of mapped landslide $\left(T_{D}\right)$ activity occurred is known. We assume that landslides occur in time according to a stationary Poisson process (Urlaub et al., 2013), such that the probability of one or more landslides over $T$ years follows an exponential distribution:

$$
P=1-\exp (-\lambda T)
$$

where $\lambda$ is termed the rate or intensity parameter. This is a time-independent distribution, meaning that the probability is constant with time. For comparison, time-dependent distributions have been previously evaluated in comparison to the exponential distribution at an Integrated Ocean Drilling Program site with repeated mass transport deposits by Geist et al. (2013). The hazard curve combines the survival function for the landslide size distribution with the overall rate of occurrence $(\alpha)$ :

$$
\lambda(a)=\alpha[1-F(a)]
$$

The overall rate can be simply thought of a $\alpha=n / T_{D}$, where $n$ is the number of landslides above the resolution threshold (Table 1). $T_{D}$ can be estimated using the age of the oldest landslide, although as described below this age is frequently unknown. However, a more complete calculation of $\alpha$ includes uncertainty 


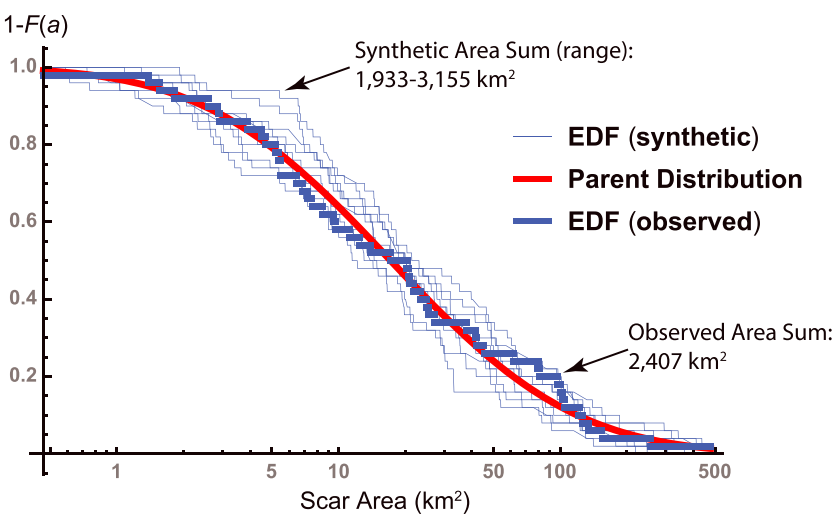

Figure 8. Survival functions for U.S. Atlantic parent distribution, the observed empirical distribution function (EDF), and 10 synthetic EDFs randomly sampled from the parent distribution. related to the open time intervals before the oldest slide and after the youngest slide (cf. Geist et al., 2013 ; Parsons, 2008). This estimate of $\alpha$ also assumes that the rate is stationary since the age of the oldest landslide (cf. Lee, 2009; Urlaub et al., 2013), which may not be valid in regions where the sedimentation rate varies quickly in geologic time, such as for glaciated margins. The empirical determination of a landslide hazard curve as outlined above is distinct from a geotechnical probabilistic approach that is primarily used for subaerial landslides. The latter relies on estimates for expected ground shaking from nearby earthquakes, slope, and physical properties including soil shear strength (e.g., Rathje et al., 2014, Saygili \& Rathje, 2009, Wang \& Rathje, 2015).

In many margins, the age of the oldest slide, as a proxy to determine the duration of mapped landslide activity, has yet to be determined. The U.S. Atlantic is one margin where the age of the oldest landslides ( $20 \mathrm{kyr})$ can be estimated (ten Brink et al., 2014) and is used to demonstrate the calculation of an offshore landslide hazard curve. A hazard curve for this margin is shown in Figure 11 (red), using the parameters estimated for the lognormal distribution (Table 1) and equations (13) and (14) above. For comparison, a hazard curve for the Queen Charlotte margin is also shown in Figure 11 (blue). In this case, we make the assumption that $T_{D}$ is constrained by the time that the Cordilleran Ice Sheet began to retreat approximately $14 \mathrm{kyr}$ ago (Clague \& James, 2002). The validity of the stationary rate assumption for this margin depends on the length of time during which sedimentation changed from glacial to interglacial rate. The hazard curves for the two data sets are truncated to the left at the minimum observed scar area determined from the minimum resolution afforded by the multibeam
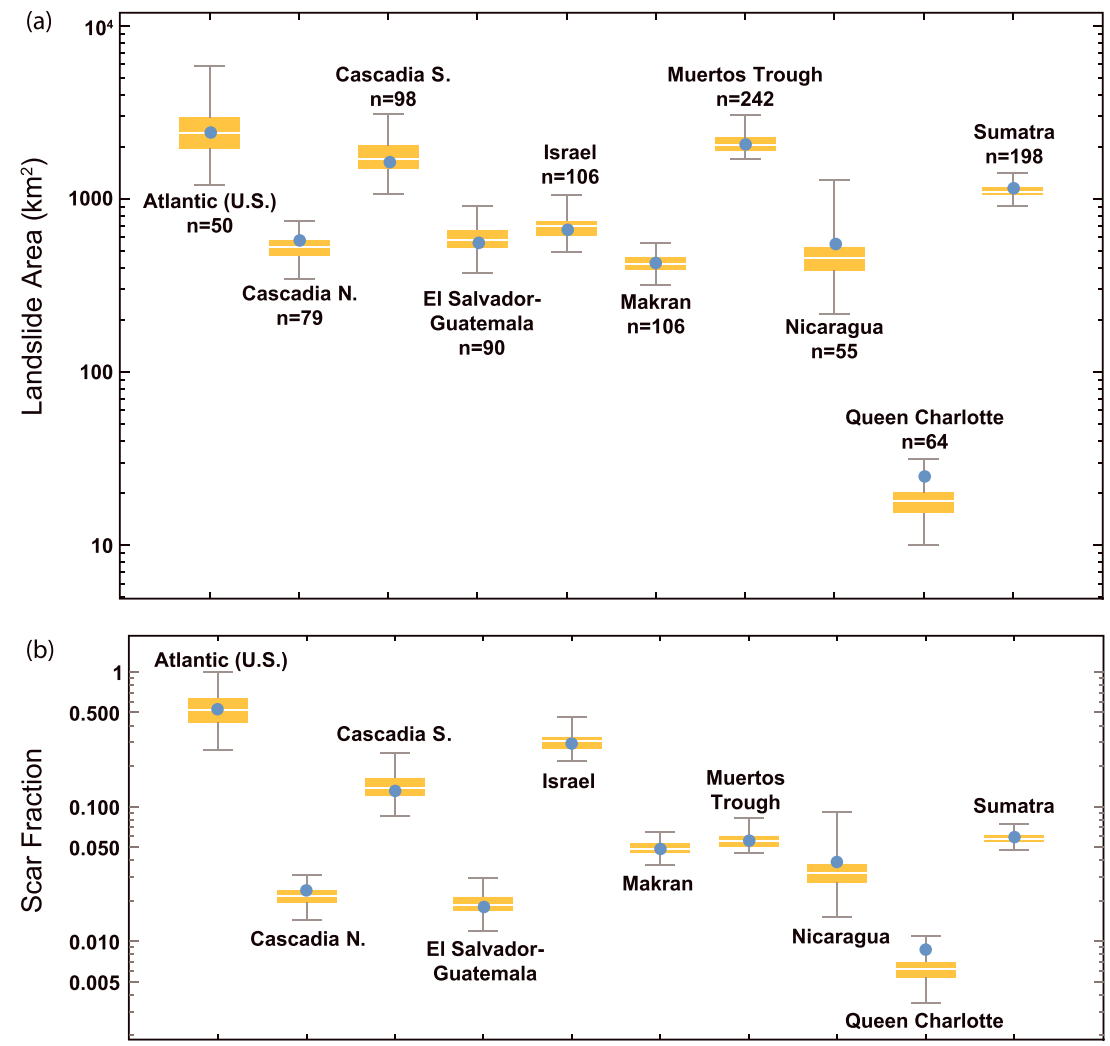

Figure 9. Box plots with logarithmic axis showing effect of finite sampling on total landslide area (a) and scar fraction (b). Orange box indicate first to third interquartile ranges (white line indicates median), and vertical lines indicate minimummaximum range. Blue dots indicate observed values. 


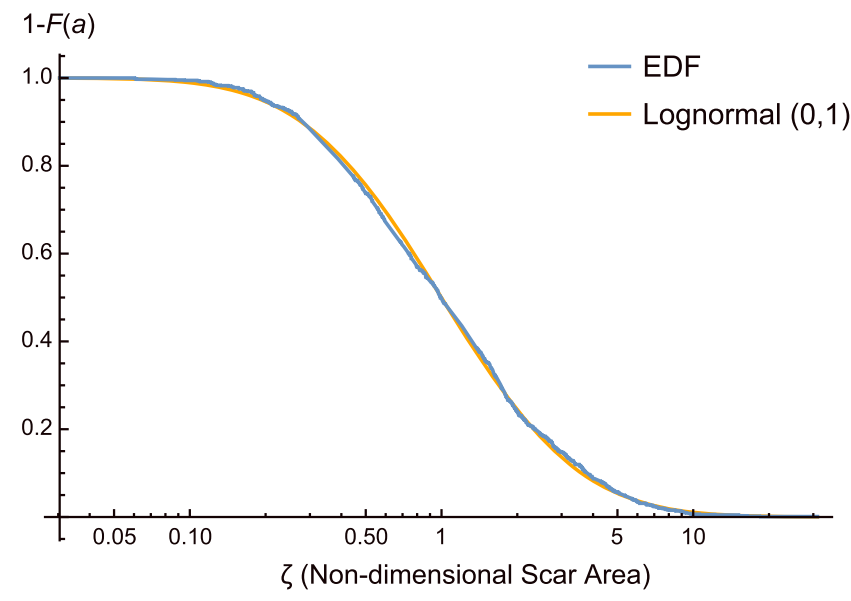

Figure 10. Aggregate empirical distribution function (EDF) from all 10 data sets (nondimensionalized) and lognormal survival function $(\mu=0, \sigma=1)$.

data (see Table 1), which varies between the data sets (described in section 3.2). The two hazard curves, representing end-member margins of the ones analyzed, are different by orders of magnitude for design probabilities of 0.001 or less (i.e., mean return times of $1 \mathrm{kyr}$ or greater), primarily because of differences in the size distributions for the two margins. One could argue that the U.S. Atlantic and Queen Charlotte margins are outliers based on the pairwise comparison tests and that the typical range is smaller than shown in Figure 11. The 10 margins analyzed in this study, however, represent a subset of all margins that have had landslide activity, making it difficult to determine whether the U.S. Atlantic and Queen Charlotte margins are true outliers.

The diverse depositional environments of the margins examined in this study may preclude a common global cause or signal for duration of the mapped landslide activity. A global correlation of landslide activity with glacial cycles and sea level has been suggested in the past, especially in the northern Atlantic (Lee, 2009). However, Urlaub et al. (2013) indicate little correlation to sea level rise and periods of rapid sedimentation. Although global landslide frequency was highest after the last glacial maximum (approximately 22-18 kyr before present) during periods of rising sea level, they indicate that correlation with landslide timing and sea level is not statistically significant. For some margins, it may be possible to constrain $T_{D}$ based on inferences on local sea level changes and depositional controls, as for the Queen Charlotte margin.

It is useful to understand how different estimates of $T_{D}$ affect the calculated landslide hazard curve. For this, we can take advantage of the fact the lognormal shape parameter $\sigma$ is similar among most of the margins, as suggested by the overlapping confidence intervals in Table 1. The exceptions are the U.S. Atlantic and Makran margins in which the $\sigma$ confidence intervals do not overlap those for all other margins. The similarity of the shape parameter among margins results in hazard curves having a similar shape when plotted with a logarithmic landslide area axis. Shown in Figure 12 is a schematic landslide hazard curve using an average value of $\sigma$. Changes in $T_{D}$ result in vertical shifts in the hazard curve $( \pm 10 \mathrm{kyr}$ shown as an example in Figure 12a), whereas changes in $\mu$ results in horizontal shifts in the hazard curve (range using $\mathrm{max} / \mathrm{min}$ values of $\mu$ in Table 1 shown in Figure 12b). This shift is also prominent in comparing the U.S. Atlantic and Queen Charlotte hazard curves in Figure 11.

To assess the total landslide hazard for a margin, one can calculate what we term the "landslide release rate," analogous to seismic moment release rate along a fault (Frohlich \& Wetzel, 2007; Kagan, 2002b; Peterson \& Seno, 1984). Landslide release rate $\dot{A}\left(\mathrm{~km}^{2} / \mathrm{kyr}\right)$ for a given mapped area is related to equation (11) by considering the time period when landslide activity takes place:

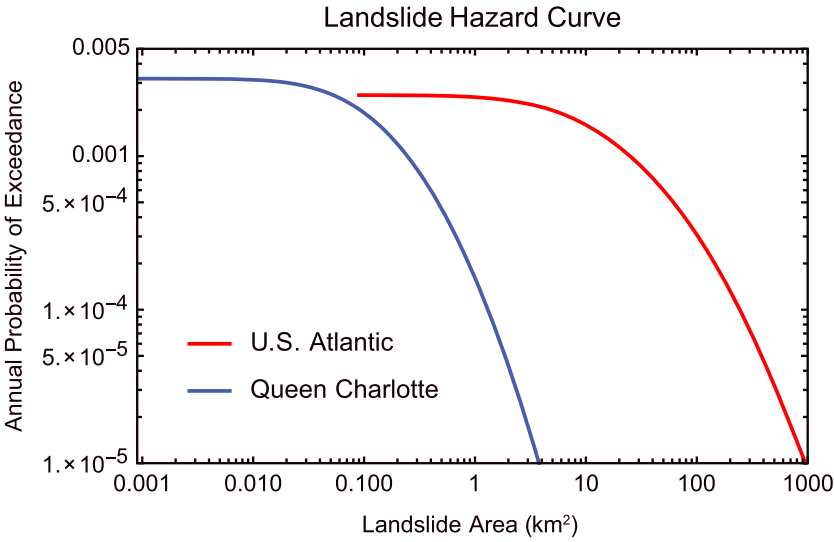

Figure 11. Landslide hazard curves for the Queen Charlotte and U.S. Atlantic margins.

$$
\dot{A}=\frac{A}{T_{D}}=\alpha \exp \left(\mu+\frac{\sigma^{2}}{2}\right)
$$

where $\alpha$ is the overall rate of landslides above the resolution threshold. As with calculating the hazard curves, the duration of landslide activity is needed to calculate this hazard metric. In contrast to the hazard curves, landslide release rate varies with the area of the margin being considered. Although the estimated landslide release rate applies only to the mapped portion of the margin, the estimate can be extrapolated to unmapped portions of the margin as long as there is confidence that the size distribution applies to the unmapped portions (see section 3.6). Landslide release rate can be normalized with respect to the mapped area, similar to how seismic moment release rate is normalized with respect to length of subduction zones in Peterson and Seno (1984). Normalized landslide release rate based on the temporal rate of landslide scar formation yield the areal 
(a)

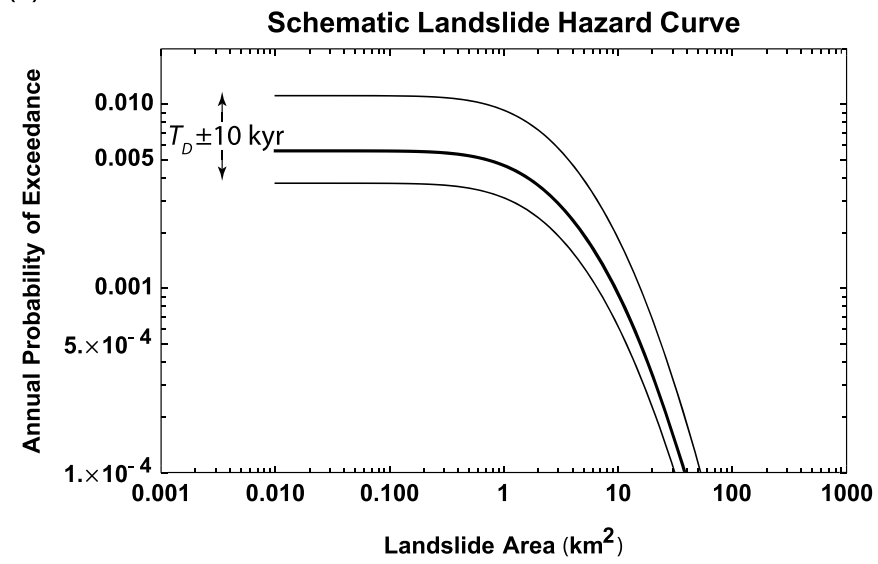

(b)

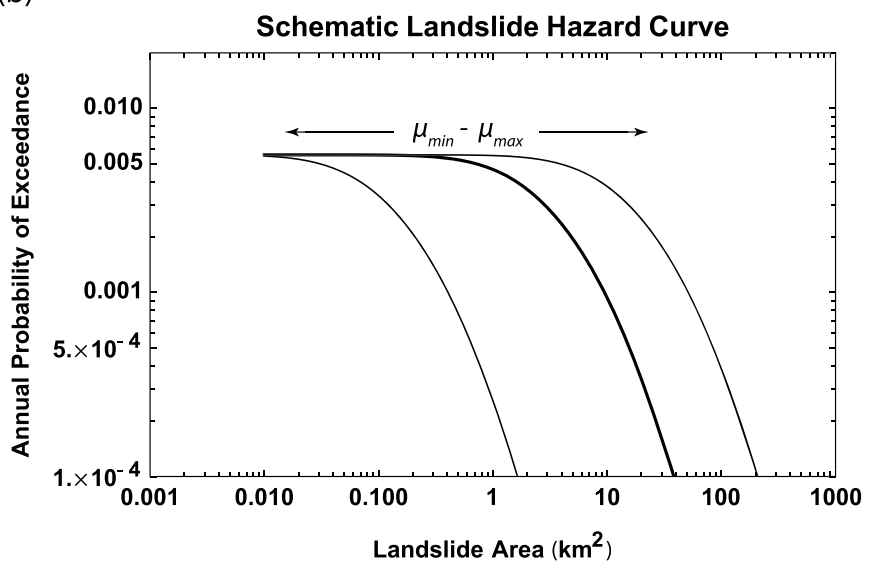

Figure 12. Effect of changes in $T_{D}$ (a) and $\mu$ (b) on calculated hazard curves, assuming constant $\sigma$. Schematic curves (heavy lines) calculated from average values of $\mu, \sigma$, and $n$ from Table 1 and $T_{D}=20$ kyr. Range is shown by thin curves.

fraction of the margin that fails in landslides over time $\left(\mathrm{kyr}^{-1}\right)$. For the Queen Charlotte and U.S. Atlantic margins, the normalized landslide release rates are $4.6 \times 10^{-4}$ and $2.9 \times 10^{-2} \mathrm{kyr}^{-1}$, respectively, using equation (15) and the same ages as for the hazard curve calculations described above. The total normalized landslide hazard for the U.S. Atlantic margin, therefore, is approximately 60 times greater than that for the Queen Charlotte margin.

\section{Discussion}

We propose that offshore landslide hazards can be quantified by an empirical hazard curve, in which the probability of exceedance is plotted as a function of landslide scar area or some other metric, such as landslide volume. There are two essential ingredients needed to develop empirical landslide hazard curves: the size distribution of mapped landslides and the duration associated with mapped landslide activity. For the former, we indicate that there are sufficient data along many mapped margins to establish the size distribution with confidence. We find that the lognormal distribution fits the data for most margins and that the lognormal parameter $\sigma$ is similar among the 10 margins examined in this study, whereas the lognormal parameter $\mu$ and mean landslide size varies significantly. Duration of landslide activity can be estimated by the age of the oldest mapped landslide for some margins, although for many margins there are few-tono absolute ages of individual landslides. Although Urlaub et al. (2013) indicate that there is little statistical confidence in global timing of landslide activity; local inferences of controlling factors for landslide triggering may be made to constrain the duration of mapped landslide activity. In places, where the duration of landslide activity can be estimated or constrained, empirical landslide hazard curves can differ significantly, primarily because of differences in the size distribution, as demonstrated in Figure 11. The information needed to calculate offshore landslide hazard curves can also be used to develop tsunami hazard curves that aggregate offshore landslide sources (Geist et al., 2009; Geist \& Lynett, 2014; Grezio et al., 2017; Lane et al., 2016).

The characteristic lognormal distribution for landslide sizes in siliciclastic material indicates that the physical factors that dictate size (e.g., seismic shaking and sedimentation rate) combine in a multiplicative relationship (Mitzenmacher, 2004; Sornette, 2004). There is also a multiplicative relationship between the two explanatory variables of sedimentation rate and mean earthquake recurrence described by ten Brink et al. (2016). In comparison, normal distributions are associated with an additive relationship and Pareto distributions, such as those that govern debris avalanches in a carbonate environment (ten Brink et al., 2006), indicate "preferential attachment" (Mitzenmacher, 2004) or are associated with the phenomenon of selforganized criticality (Sornette, 2004). Compared to offshore landslides, subaerial landslide may be influenced more by the topography, giving rise to a power law relations of sizes in the case of landslides associated with the 1994 Northridge earthquake (ten Brink, Barkan, et al., 2009). Furthermore, the similarity of the 
lognormal parameter $\sigma$ suggests that the physical factors that govern landslide failure in an offshore siliciclastic environment are similar among margins (cf. Limpert et al., 2001). The variability in lognormal parameter $\mu$ can be tied to the explanatory variable of mean interseismic sediment thickness proposed by ten Brink et al. (2016). They suggest that decreasing the mean interevent time for earthquakes increases slope stability through repeated decreases in void ratio and pore pressure. We suggest that the smaller mean landslide size in regions of short mean earthquake interevent time is also linked to this slope stability mechanism.

The lognormal distribution has very low weight near 0 , which is the primary difference between it and exponential or power law distributions. Is there a physical reason for a minimum submarine landslide size, or is this due to our inability to resolve small landslide areas on multibeam bathymetry maps? ten Brink et al. (2009) used slope stability analysis to calculate the expected failure area of submarine landslides along the U.S. Atlantic margin as a function of earthquake magnitude and slope angle. They showed that landslides are not expected to form at magnitudes $<4.5-5$ and at slope angles $\leq 6^{\circ}$ because the peak ground acceleration is too small to cause significant displacement of the failed sediments. For the Scotian margin, Mosher et al. (1994) determined a minimum magnitude of 5 from geotechnical analysis of cores. Keefer (1984) showed that earthquakes with local magnitude $M_{L}<4$ in the U.S. do not generate subaerial landslides.

A modified inverse power law is often used to model the observed distribution of landslides on land (e.g., Malamud et al., 2004, Stark \& Hovius, 2001). This distribution can be explained by two different causes. First, many of the subaerial landslides are triggered by pore pressure fluctuations induced by heavy rain or snowfall, not by ground acceleration. Second, ten Brink, Barkan, et al. (2009) have shown that for earthquake-induced failures, such as associated with the 1994 Northridge earthquake, landslide distributions follow the same distribution as for the topographic slopes in the area. In other words, slope failure size is limited by the slope area available to fail, not by ground acceleration. The maximum total area that encompasses subaerial failures due to earthquake shaking (Keefer, 1984; Rodriguez et al., 1999) is, in fact, comparable to the area calculated for the Atlantic continental slope, because both reflect the ground acceleration attenuation with distance (ten Brink, Barkan, et al., 2009). In summary, the lognormal size distribution reflects the minimum earthquake size capable of causing ground failure.

For margins where only a small number of landslides have been mapped, estimating the parameters for a highly skewed distribution such as the lognormal distribution can present several difficulties. For small sample numbers (i.e., less than those given in Table 1), the sample mean will be biased lower than the true mean and closer to the mode of the distribution. The greater the skewness of a distribution implies a greater separation between the mode and mean. In many cases, the tail of the distribution will not be sufficiently sampled and the empirical distribution will appear depleted relative to the parent distribution and may even be mistaken for a normal (nonskewed) distribution. In this case, large-sized events may appear to be outliers, when in fact they must be included when estimating the distribution. This is particularly a problem for Pareto-type distribution (Geist \& Parsons, 2014) but is also an issue for highly skewed lognormal distributions (i.e., $\sigma>0.5$ ) such as for the offshore landslide sizes examined here.

Progress in the assessment of offshore landslide hazards will rely on the acquisition of absolute age dates for mapped landslides. As previously noted (Geist et al., 2009) and emphasized in this paper, these dates are essential for determining the rate of landslide activity. In addition, age dates of individual events help determine whether landslides occur as a Poisson process (Urlaub et al., 2013) or if a time-dependent probability model is more appropriate (Geist et al., 2013). Absolute age dating offshore landslides using cores is complex and difficult. Ideally, ages of sediment both underlying and overlying the landslide deposit or scar yields a time bracket when the slide occurred, although location of the core in relation to the depositional environment of preslide and postslide sediment introduces large uncertainties (Urlaub et al., 2013).

\section{Conclusions}

The previous study by ten Brink et al. (2016) established a relationship between the mean interseismic accumulation of sediment and the total landslide scar fraction for an offshore margin. In this study, we demonstrate that the underling size distribution for landslides along the 10 margin examined by ten Brink et al. (2016) is lognormal. A maximum likelihood method is used to establish lognormal parameters and 
confidence intervals. Whereas the lognormal $\sigma$ parameter is similar among the 10 margins, the lognormal $\mu$ parameter, as well as the mean scar area, varies significantly and is likely tied to mean interseismic sediment accumulation. We compare the lognormal probability model to two other models (Weibull and tapered Pareto) and find that lognormal provides the best fit, except for the northern Cascadia margin where the Weibull model fits the data slightly better. We demonstrate that offshore hazard curves can be developed, if some information constraining the duration of mapped landslide activity is known. Hazard curves are developed for the two end-member size distributions, U.S. Atlantic and Queen Charlotte margins, using available information and assumptions of landslide activity. For design probabilities of 0.001 or less (mean return times of $1 \mathrm{kyr}$ or greater), the hazard between the two margins is different by at least an order of magnitude. Further age dating of offshore landslides is critical for more accurately defining the direct and indirect (e.g., tsunamis) hazard posed by offshore landslides.

Acknowledgments

The authors gratefully acknowledge the constructive comments of this manuscript by Joshu Mountjoy, Tom Parsons, and anonymous reviewer. We also thank Yehuda Ben Zion for managing this manuscript and the scientists who provided the bathymetry data. Margin and landslide polygon shape files and information on bathymetry data sources are available at GSA Repository item number 2016187.

\section{References}

Aitkin, M. (2010). Statistical inference: An integrated Bayesian/likelihood approach (236 pp). Boca Raton, FL: CRC Press. https://doi.org/ 10.1201/EBK1420093438

Burnham, K. P., \& Anderson, D. R. (2010). Model selection and multimodel inference (2nd ed., Vol. 488). New York: Springer.

Chaytor, J., ten Brink, U. S., Solow, A. R., \& Andrews, B. D. (2009). Size distribution of submarine landslides along the U.S. Atlantic Margin. Marine Geology, 264(1-2), 16-27. https://doi.org/10.1016/j.margeo.2008.08.007

Choi, B. H., Hong, S. J., \& Pelinovsky, E. (2006). Distribution of runup heights of the December 26, 2004 tsunami in the Indian Ocean. Geophysical Research Letters, 33, L13601. https://doi.org/10.1029/2006GL025867

Choi, B. H., Pelinovsky, E., Ryabov, I., \& Hong, S. J. (2002). Distribution functions of tsunami wave heights. Natural Hazards, 25(1), 1-21. https://doi.org/10.1023/A:1013379705323

Clague, J. J., \& James, T. S. (2002). History and isostatic effects of the last ice sheet in southern British Columbia. Quaternary Science Reviews, 21(1-3), 71-87. https://doi.org/10.1016/S0277-3791(01)00070-1

Conover, W. J. (1971). Practical nonparametric statistics (Vol. 462). New York: John Wiley and Sons Inc.

Frohlich, C., \& Wetzel, L. R. (2007). Comparison of seismic moment release rates along different types of plate boundaries. Geophysical Journal International, 171(2), 909-920. https://doi.org/10.1111/j.1365-246X.2007.03550.x

Geist, E. L., Chaytor, J. D., Parsons, T., \& ten Brink, U. (2013). Estimation of submarine mass failure probability from a sequence of deposits with age dates. Geosphere, 9(2), 287-298. https://doi.org/10.1130/GES00829.1

Geist, E. L., \& Lynett, P. J. (2014). Source processes for the probabilistic assessment of tsunami hazards. Oceanography, 27(2), 86-93. https://doi.org/10.5670/oceanog.2014.43

Geist, E. L., \& Parsons, T. (2014). Undersampling power-law size distributions: Effect on the assessment of extreme natural hazards. Natural Hazards, 72(2), 565-595. https://doi.org/10.1007/s11069-013-1024-0

Geist, E. L., Parsons, T., ten Brink, U. S., \& Lee, H. J. (2009). Tsunami probability. In E. N. Bernard \& A. R. Robinson (Eds.), The sea, v. 15 (pp. 93-135). Cambridge, MA: Harvard University Press.

Gibbons, J. D., \& Chakraborti, S. (2004). Nonparametric statistical inference (4th ed., p. 645). CRC Press.

Grezio, A., Babeyko, A., Baptista, M. A., Behrens, J., Costa, A., Davies, G., et al. (2017). Probabilistic tsunami hazard analysis (PTHA): Multiple sources and global applications. Reviews of Geophysics, 55, 1158-1198. https://doi.org/10.1002/2017RG000579

Hosking, J. R. M. (1990). L-moments: Analysis and estimation of distributions using linear combinations of order statistics. Journal of the Royal Statistical Society. Series B, 52(1), 105-124. https://doi.org/10.1111/j.2517-6161.1990.tb01775.x

Hurvich, C. M., \& Tsai, C.-L. (1989). Regression and time series model selection in small samples. Biometrika, 76(2), 297-307. https://doi. org/10.1093/biomet/76.2.297

Kagan, Y. Y. (2002a). Seismic moment distribution revisited: I. Statistical results. Geophysical Journal International, 148(3), 520-541. https://doi.org/10.1046/j.1365-246x.2002.01594.x

Kagan, Y. Y. (2002b). Seismic moment distribution revisited: II. Moment conservation principle. Geophysical Journal International, 149(3), 731-754. https://doi.org/10.1046/j.1365-246X.2002.01671.x

Keefer, D. K. (1984). Landslides caused by earthquakes. Geological Society of America Bulletin, 95(4), 406-421. https://doi.org/10.1130/ 0016-7606(1984) $95<406: \mathrm{LCBE}>2.0 . \mathrm{CO} ; 2$

Kim, D., Kim, B. J., Lee, S.-O., \& Cho, Y.-S. (2014). Best-fit distribution and log-normality for tsunami heights along coastal lines. Stochastic Environmental Research and Risk Assessment, 28(4), 881-893. https://doi.org/10.1007/s00477-013-0778-y

Lane, E. M., Mountjoy, J. J., Power, W. L., \& Mueller, C. (2016). Probabilistic hazard of tsunamis generated by submarine landslides in the Cook Strait Canyon (New Zealand). Pure and Applied Geophysics, 173(12), 3757-3774. https://doi.org/10.1007/s00024-016-1410-0

Lee, H., Orzech, K., Locat, J., Konrad, J., \& Boulanger, E. (2004). Seismic strengthening, a conditioning factor influencing submarine landslide development. Paper presented at 57th Canadian Geotechnical Conference. Quebec: Can. Geotech. Soc.

Lee, H. J. (2009). Timing of occurrence of large submarine landslides on the Atlantic Ocean margin. Marine Geology, 264(1-2), 53-64. https://doi.org/10.1016/j.margeo.2008.09.009

Limpert, E., Stahel, W. A., \& Abbt, M. (2001). Log-normal distributions across the sciences: Keys and clues. Bioscience, 51(5), 341-352. https://doi.org/10.1641/0006-3568(2001)051[0341:LNDATS]2.0.CO;2

Malamud, B. D., Turcotte, D. L., Guzzetti, F., \& Reichenbach, P. (2004). Landslide inventories and their statistical properties. Earth Surface Processes and Landforms, 29(6), 687-711. https://doi.org/10.1002/esp.1064

McAdoo, B., Pratson, L., \& Orange, D. (2000). Submarine landslide geomorphology, U.S. continental slope. Marine Geology, 169(1-2), 103-136. https://doi.org/10.1016/S0025-3227(00)00050-5

Mitzenmacher, M. (2004). A brief history of generative models for power law and lognormal distributions. Internet Mathematics, 1(2), 226-251. https://doi.org/10.1080/15427951.2004.10129088

Mosher, D. C., Moran, K., \& Hiscott, R. N. (1994). Late Quaternary sediment, sediment mass flow processes and slope stability on the Scotian Slope, Canada. Sedimentology, 41(5), 1039-1061. https://doi.org/10.1111/j.1365-3091.1994.tb01439.x 
ten Brink, U. S., Andrews, B., \& Miller, N. (2016). Seismicity and sedimentation rate effects on submarine slope stability. Geology, 44(7), 563-566. https://doi.org/10.1130/G37866.1

ten Brink, U. S., Barkan, R., Andrews, B. D., \& Chaytor, J. D. (2009). Size distributions and failure initiation of submarine and subaerial landslides. Earth and Planetary Science Letters, 287(1-2), 31-42. https://doi.org/10.1016/j.epsl.2009.07.031

ten Brink, U. S., Chaytor, J. D., Geist, E. L., Brothers, D. S., \& Andrews, B. D. (2014). Assessment of tsunami hazard to the U.S. Atlantic margin. Marine Geology, 353, 31-54. https://doi.org/10.1016/j.margeo.2014.02.011

ten Brink, U. S., Geist, E. L., \& Andrews, B. D. (2006). Size distribution of submarine landslides and its implication to tsunami hazard in Puerto Rico. Geophysical Research Letters, 33, L11307. https://doi.org/10.1029/2006GL026125

ten Brink, U. S., Lee, H. J., Geist, E. L., \& Twichell, D. C. (2009). Assessment of tsunami hazard to the U.S. Atlantic Coast using relationships between submarine landslides and earthquakes. Marine Geology, 264(1-2), 65-73. https://doi.org/10.1016/j.margeo.2008.05.011

Parsons, T. (2008). Monte Carlo method for determining earthquake recurrence parameters from short paleoseismic catalogs: Example calculations for California. Journal of Geophysical Research, 113, B03302. https://doi.org/10.1029/2007JB004998

Pawitan, Y. (2001). In all likelihood: Statistical modelling and inference using likelihood (528 pp.). Oxford: Oxford University Press.

Peterson, E. T., \& Seno, T. (1984). Factors affecting seismic moment release rates in subduction zones. Journal of Geophysical Research, 89(B12), 10,233-10,248. https://doi.org/10.1029/JB089iB12p10233

Rathje, E. M., Wang, Y., Stafford, P. J., Antonakos, G., \& Saygili, G. (2014). Probabilistic assessment of the seismic performance of earth slopes. Bulletin of Earthquake Engineering, 12(3), 1071-1090. https://doi.org/10.1007/s10518-013-9485-9

Rodriguez, C. E., Bommer, J. J., \& Chandler, R. J. (1999). Earthquake-induced landslides: 1980-1997. Soil Dynamics and Earthquake Engineering, 18(5), 325-346. https://doi.org/10.1016/S0267-7261(99)00012-3

Saygili, G., \& Rathje, E. M. (2009). Probabilistically based seismic landslide hazard maps: An application in Southern California. Engineering Geology, 109(3-4), 183-194. https://doi.org/10.1016/j.enggeo.2009.08.004

Sornette, D. (2004). Critical phenomena in natural sciences (2nd ed., p. 528). Berlin: Springer-Verlag.

Stark, C. P., \& Hovius, N. (2001). The characterization of landslide size distributions. Geophysical Research Letters, 28(6), 1091-1094. https://doi.org/10.1029/2000GL008527

Strozyk, F., Strasser, M., Förster, A., Kopf, A., \& Huhn, K. (2010). Slope failure repetition in active margin environments: Constraints from submarine landslides in the Hellenic fore arc, eastern Mediterranean. Journal of Geophysical Research, 115, B08103. https://doi.org/ 10.1029/2009JB006841

Urgeles, R., \& Camerlenghi, A. (2013). Submarine landslides of the Mediterranean Sea: Trigger mechanisms, dynamics, and frequencymagnitude distribution. Journal of Geophysical Research: Earth Surface, 118, 2600-2618. https://doi.org/10.1002/2013JF002720

Urlaub, M., Talling, P. J., \& Masson, D. G. (2013). Timing and frequency of large submarine landslides: Implications for understanding triggers and future geohazard. Quaternary Science Reviews, 72, 63-82. https://doi.org/10.1016/j.quascirev.2013.04.020

Vere-Jones, D., Robinson, R., \& Yang, W. (2001). Remarks on the accelerated moment release model: Problems of model formulation, simulation and estimation. Geophysical Journal International, 144(3), 517-531. https://doi.org/10.1046/j.1365-246x.2001.01348.x

Wang, Y., \& Rathje, E. M. (2015). Probabilistic seismic landslide hazard maps including epistemic uncertainty. Engineering Geology, 196 313-324. https://doi.org/10.1016/j.enggeo.2015.08.001

Zhou, X.-H., Gao, S., \& Hui, S. L. (1997). Methods for comparing the means of two independent log-normal samples. Biometrics, 53(3), 1129-1135. https://doi.org/10.2307/2533570 